\title{
1 Moderate consistency in smooth newt behaviour
}

3 Petr Chajma ${ }^{1, *}$, Oldřich Kopeckýn ${ }^{2}$, Jiří $\operatorname{Vojar}^{1}$

5 1-Department of Ecology, Faculty of Environmental Sciences, Czech University of Life

6 Sciences Prague, Kamýcká 129, Praha - Suchdol, 165 00, Czech Republic

7 2-Department of Zoology and Fish Farming, Faculty of Agrobiology, Food and Natural

8 Resources, Czech University of Life Sciences Prague, Kamýcká 129, Praha - Suchdol,

9165 00, Czech Republic

$10 *$ Corresponding author; e-mail: chajmap@fzp.czu.cz

\section{Abstract}

13 Behavioural consistency (i.e., personality) is a novel field of research in amphibians.

14 Current published studies often address only one or two aspects of personality and

15 therefore cannot assess more complex relationships and behavioural syndromes. This is

16 the first study focusing on all relevant behavioural traits and their relationships in

17 urodele amphibians. Based on the three trials of the experiment, we examined the

18 consistency of activity (time spent moving), boldness (latency of the first movement and

19 time spent escaping) and exploration (number of visited segments of testing arena) of 42

20 smooth newts (Lissotriton vulgaris). Individual consistency, calculated through the

21 intraclass correlation coefficient (ICC), was low in newt activity $($ ICC $=0.192$ ) and

22 moderate in boldness (0.476) and exploration (0.403). Activity was moderately

23 consistent for each trial (0.425), indicating a possible habituation, supported by a

24 decrease of mean activity throughout the trials. Correlation of the behavioural traits 
25 studied suggests the presence of a behavioural syndrome, which potentially shaped the

26 traits together. Our findings suggest the need for a complex approach to the study of

27 amphibian personality and the need for standardized methodology, which would solve

28 the current difficulties in comparing published results.

\section{Introduction}

30 Behavioural consistency (i.e., personality) is a well-known phenomenon studied in 31 many taxa (Gosling 2001; Sih et al. 2004; Réale et al. 2007; Garamszegi et al. 2013)

32 and recently studied in amphibians (Aragón 2011; Koprivnikar et al. 2011; Maes et al.

33 2012; Wilson and Krause 2012; Brodin et al. 2013; Carlson and Langkilde 2013,

34 2014a). Consistency in the expression of behavioural traits over time and in different

35 situations, as well as the correlation of those traits, i.e., behavioural syndrome (Sih et al.

36 2004), is often linked to survival in predator-prey situations (Dingemanse and de Goede

37 2004; Carlson and Langkilde 2014b) (but see Carlson and Langkilde 2014a),

38 reproductive success (Dingemanse and Réale 2005; Cole and Quinn 2014), disease risk

39 (Koprivnikar et al. 2011) and dispersal tendencies (Cote et al. 2010, 2013; Maes et al.

40 2012; Brodin et al. 2013). Therefore, animal personality plays an important part in

41 individual life histories and should be inspected and carefully considered when dealing

42 with most aspects of animal ecology.

43 Amphibian personality research, however, is limited and includes mostly studies

44 performed on anurans (for a thorough review, see Kelleher et al. 2017). In contrast,

45 there are considerably fewer studies for urodeles (Sih et al. 2003; Aragón 2011; Gifford

46 et al. 2014; Winandy and Denoël 2015) and none for caecilians. Existing amphibian

47 studies most commonly address the consistency of activity, boldness and exploration

48 and have yet to consider the consistency of remaining personality traits - aggressiveness 
49 and sociability (Kelleher et al. 2017). Most of these studies (none of which consider

50 urodeles), however, address only one or two of these behavioural traits (axis of

51 personality) and usually cover some specific problem, not personality per se. There are

52 also differences in approaches to behavioural consistency, because some studies cover

53 differences across time (e.g. Wilson and Krause 2012; Maes et al. 2012; Carlson and

54 Langkilde 2013; Brodin et al. 2013), while others consider differences across situations

55 (e.g. Sih et al. 2003; Aragón 2011; Koprivnikar et al. 2011).

56 Therefore, the aim of our study was to measure the consistency of main behavioural

57 traits-activity, exploration and boldness-in one experiment to examine the main

58 types of behavioural responses and to focus only on temporal consistency while

59 reducing other factors. Furthermore, we wanted to assess the correlations between these

60 behaviour types (i.e., the existence of behavioural syndrome).

61 Methods

62 Experimental design

63 The experiment was carried out in laboratory conditions at the Czech University of Life

64 Sciences in Prague. For a model organism, we chose the urodele that was most

65 abundant locally, the smooth newt (Lissotriton vulgaris). At the start of the reproductive

66 season in the beginning of May 2017, 21 males and 21 females were captured by nets in

67 a single pond in the Stará Lysá village in the Central Bohemia region. The newts were

68 housed separately in plastic containers of dimensions $18 \times 12 \times 14 \mathrm{~cm}$ that were filled

69 with aged tap water, and the newts were fed Daphnia and Chironomidae larvae ad

70 libitum. The air temperature in the laboratory was constant and set to $17^{\circ} \mathrm{C}$. Sufficient

71 light intensity in a diurnal cycle was provided by the translucent roof of the laboratory. 
72 The experiment itself was conducted between $13^{\text {th }}$ and $27^{\text {th }}$ May in two experimental

73 arenas made of non-transparent round green water barrels with bottom diameters of 80

$74 \mathrm{~cm}$. Using a non-toxic waterproof marker, a square grid of $7 \mathrm{~cm}$ segments was drawn at

75 the bottom to better assess the position of each newt. The arena was filled with $5 \mathrm{~cm}$ of

76 cold tap water $\left(10.8-11.2^{\circ} \mathrm{C}\right)$, and after each recording, the water was changed, and the

77 arena was thoroughly cleaned with a clean sponge, pressurized water and then left to

78 dry to eliminate any potential chemical cues that remained from the previous individual

79 tested.

80 Each trial of the experiment was 12 minutes long. Behaviour was recorded at 25 frames

81 per second with a full HD camera, positioned approximately $150 \mathrm{~cm}$ above the water

82 level. Newts were separately inserted under the transparent glass dome $(10 \mathrm{~cm}$

83 diameter) into the centre of the arena and left to calm down for the first two minutes.

84 Then, the dome was carefully removed in a motion perpendicular to the ground, and the

85 recording was initiated. To measure the temporal repeatability of the behaviour, each

86 individual was recorded three times with a six day gap between each recording, which

87 was the longest gap possible before the newts started to shift to the terrestrial phase of

88 the season. Unfortunately, three videos were lost due to technical difficulties in the last

89 trial of the experiment, so the total number of analysed videos was 123.

90 Three types of behaviour (personality traits) were tracked: activity, exploration and

91 boldness. Activity was measured as the amount of time [s] during which the individual

92 moved. Furthermore, the movement activity was divided to walking and swimming to

93 distinguish the role of each in total activity and the consistency of each as well as to

94 determine the consistency of the choice of locomotion (i.e. the proportion of activity

95 spent by walking). Exploration was recorded as the number of grid blocks that an 
96 individual entered. For the sake of better comparison with the other studies,

97 boldness/shyness was measured as the latency of the first movement [s] (the most

98 common but imprecise measure of boldness, see Discussion) as well as the time [s]

99 spent at the outermost edge of the arena (our preferred measure). Staying in its vicinity

100 (thigmotaxis) can be interpreted as an escape response and therefore can be a valuable

101 measure of shyness (Burns 2008; Harris et al. 2009; Carlson and Langkilde 2013).

102 Behaviour was scored manually by the same person using the software Observer XT v.

10310 (Noldus 2010). The study was carried out in accordance with permit SZ-

104 092744/2012KUSK/3 issued by the Regional Office of the Central Bohemian Region of

105 the Czech Republic and approved by an institutional committee based on the

106 institutional accreditation No. 63479/2016-MZE-17214 of Ministry of Agriculture of

107 the Czech Republic.

108 Data analysis

109 To test the differences in activity, time spent walking, swimming, number of visited 110 squares (exploration), latency of the first movement (boldness) and time spent near the

111 outermost edge of arena (shyness) between trials and sexes (independent variables), we

112 created separate linear mixed effects models (LMM) for each mentioned characteristic

113 (dependent variable) fitted by restricted maximum likelihood (REML) with the

114 individual (1-42) as random intercept. Apart from mentioned variables, we also tested

115 the dependency of the proportion of walking activity (i.e. time spent walking divided by

116 time spent active) of each newt on the same fixed (trial and sex) and random effects

117 (individual). This was done to assess if the preferred type of locomotion differed

118 between sexes and trials. Albeit modelling proportions, this particular model reasonably

119 met the assumptions for LMM. 
120 Each model was also tested for the effect of time of day, when the experimental trial

121 took place. Because the dependency on time is rarely linear, we decomposed this

122 variable to sine and cosine of time in radians to accommodate for its periodical nature.

123 Upon meeting all underlying assumptions, models were evaluated using Type II Wald

124 Chi-squared tests. The time of day, nor the sex of the newts didn't affect any of tested

125 variables (see Supplementary information for the details) and were therefore not

126 included in repeatability analyses.

127 Individual consistency (repeatability) in measured traits (dependent variables from

128 previous models) was calculated using the intraclass correlation coefficient (ICC),

129 computed from the variance components of models similar to previous ones, but with

130 no fixed effects and the trial number as a second random variable. Note that adding trial

131 number as a random intercept allowed us to estimate its' consistency, i.e. the between

132 subject similarity in measured traits expression during each trial of the experiment and

133 estimate individual repeatability stripped from the effect of trial order.

134 Confidence intervals (CI) for the ICC were estimated by parametric bootstrapping with

1351000 iterations (for details see Nakagawa and Schielzeth 2010). Confidence interval for

136 the proportion of walking activity was estimated from the fixed intercept of the linear

137 mixed effects model with the individual and trial as random intercepts, using the profile

138 likelihood method.

139 The existence of behavioural syndromes was tested using Kendall's coefficient of 140 concordance, rather than ICC, because the interest lays in the ranks of responses, rather

141 than their absolute value. Pairwise similarities were analysed using Pearson's

142 correlation coefficient. All statistical analyses were performed in R 3.3.1 (R Core Team 
143 2016) using lme4 (Bates et al. 2015), car (Fox and Weisberg 2011) and rptR (Stoffel et

144 al. 2017) packages at the level of significance $\alpha=0.05$.

\section{Data Availability}

146 The datasets analysed during the current study are available in the Open Science

147 Framework repository, https://osf.io/nbfk6/.

\section{$148 \quad$ Results}

149 Activity

150 Mean activity significantly differed between trials (for details, see Supplementary

151 information). The initial mean activity of 309.9 seconds decreased by $32 \%$ in the

152 second trial and by $20 \%$ in the third trial. Although with a low ICC (0.192), individual

153 activity was significantly repeatable. Activity among the newts was also significantly

154 repeatable within trials of the experiment $(I C C=0.416)$ (for details, see Table 1a and

155 Table $1 b)$.

Table 1a. $\quad$ Individual repeatability of behavioural traits

\begin{tabular}{lll}
\hline Variable & ICC & CI \\
\hline Activity & 0.192 & {$[0.06,0.42]$} \\
Walking & 0.254 & {$[0.05,0.45]$} \\
Swimming & 0.385 & {$[0.18,0.57]$} \\
Walking & & \\
proportion & 0.373 & {$[0.17,0.55]$} \\
Squares explored & 0.403 & {$[0.2,0.59]$} \\
Latency of the & & \\
first movement & 0.121 & {$[0,0.32]$} \\
Thigmotaxis & 0.476 & {$[0.27,0.64]$}
\end{tabular}

Table 1b. $\quad$ Trial repeatability of behavioural traits

\begin{tabular}{lrl}
\hline Variable & ICC & CI \\
\hline Activity & 0.416 & {$[0.01,0.73]$} \\
Walking & 0.058 & {$[0,0.22]$} \\
Swimming & 0.156 & {$[0,0.42]$} \\
Walking & & \\
proportion & 0.046 & {$[0,0.18]$} \\
$\begin{array}{l}\text { Squares explored } \\
\text { Latency of the }\end{array}$ & 0.051 & {$[0,0.18]$} \\
first movement & 0 & {$[0,0.05]$} \\
Thigmotaxis & 0.022 & {$[0,0.12]$}
\end{tabular}

156 Activity - time spent moving

157 Walking - time spent walking

158 Swimming - time spent swimming

159 Walking proportion - proportion of activity spent walking

160 Squares explored - number of visited squares

161 Latency of the first movement - time spent idle, before the first movement

162 Thigmotaxis - time, spent in the outermost part of the test arena

163 ICC - intraclass correlation coefficient

164 CI $-95 \%$ Confidence intervals 
165 When the activity was divided into walking and swimming, walking was the preferred

166 type of locomotion taking up $71 \%$ of time spent active $(C I=[0.583,0.840])$. Both the

167 amount of walking $(P<0.01)$ and swimming $\left(P<10^{-4}\right)$ differed significantly between

168 the trials of the experiment. The portion of activity spent by walking, however,

169 increased only slightly during the second and third trials $(P=0.05)$. Albeit significant,

170 the repeatability of walking was relatively low for each newt $(I C C=0.254)$ and non-

171 significant for the trial $(I C C=0.058)$. Swimming was more repeatable than walking and

172 was significant for each individual $(I C C=0.385)$ but not each trial $(I C C=0.156)$. The

173 proportion of walking activity was fairly consistent for individuals $($ ICC $=0.373)$ but

174 not for each trial $(I C C=0.046)$ (for details, see Table 1a and Table $1 \mathrm{~b})$.

175 Exploration

176 Similar to activity, there was a significant difference between each trial of the

177 experiment $(P=0.01$, see Supplementary information). The initial mean of 27.8

178 explored squares decreased by $2.5 \%$ in the second and by $18 \%$ in the third trial.

179 Exploration was significantly repeatable for each newt with a moderate ICC (0.403). In

180 contrast to activity, there was no repeatability for the exploration in each trial $(I C C=$

181 0.051, see Table 1a and Table 1b).

182 Boldness

183 Boldness was measured as the latency to move and the time spent with an escape

184 response. Latency to move was not dependent on any tested variables (see

185 Supplementary information). Time spent with an escape response was marginally

186 independent of the trial $(P=0.06)$. The initial mean time spent with the escape response

187 of 226.9 seconds decreased by $5.5 \%$ in the second trial and then rose by $30 \%$ in the

188 third trial. The repeatability of latency and time spent escaping was similar for each trial 
189 of the experiment, but not for individual newts. Latency was not repeatable for both

190 newt $(I C C=0.121)$ and trial $(I C C=0)$. Time spent escaping was, on the other hand,

191 moderately repeatable for each newt $(I C C=0.476)$ and not repeatable for each trial

$192($ ICC $=0.022$, see Table $1 \mathrm{a}$ and Table $1 \mathrm{~b})$.

\section{Correlated behaviour}

194 The similarity in mean activity, exploration and time spent escaping (shyness) of

195 individuals was relatively high (Kendall's $W=0.716, P<10^{-13}$ ). Pairwise correlations

196 showed a strong positive relationship between activity and time spent escaping $(r=$

$\left.1970.734, P<10^{-6}\right)$ and a moderate correlation between activity and exploration $(r=0.539$,

$198 P=0.0002)$ and between time spent escaping and exploration $(r=0.405, P=0.0078)$.

\section{Discussion}

200 Observed behavioural responses of studied newts were moderately individually

201 consistent for swimming activity, proportion of walking activity, exploration and escape

202 response (thigmotaxis). Repeatability of activity as a whole was lower because of the

203 less repeatable walking activity that was more prevalent than swimming activity. The

204 consistency of the proportion of walking, i.e., the choice of locomotion type, however,

205 suggests that even when activity levels change, the preferred type of locomotion does

206 not. The activity was moderately consistent for each trial, meaning it decreased for all

207 newts similarly during each trial of the experiment. Boldness was consistent only if

208 measured as thigmotaxis (i.e., time spent with escape response), not as the latency of the

209 first movement. Studied behaviour responses also did not differ between sexes (as

210 opposed to Aragón 2011) and were unaffected by the time of day when experiment

211 started. 
212 According to recent review of Kelleher et al. (2018), a total of six studies tested the

213 consistency of expressed behavioural traits in larval and eight in post-metamorphic

214 amphibians. Up to date, there is, however, no review comparing the magnitude of

215 behavioural trait consistency of said studies. Therefore, in attempt to compare our

216 results to the remaining works, we reviewed available literature in Table 2. Out of 16

217 reviewed studies, five addressed urodeles, but only three provided repeatability

218 estimates, none of which had more than two repeated measurements. Furthermore only

219 one of described urodele studies provided evidence for temporal repeatability of a

220 personality trait (exploration) (Gifford et al. 2014). If we include the works that

221 compare behaviour in different odour treatments (no, conspecific or predator odour),

222 observed repeatability in our study was lower for general activity and similar for

223 boldness and exploration, though the unbiased comparison is impossible, due to

224 substantial differences in used methods.

225 Activity

226 Taking into account all of the reviewed studies for both anuran and urodelan 227 amphibians, the repeatability of activity varied odour treatments (Urszán et al. 2015a),

228 arena structure (Smith and Doupnik 2005), breeding origin - wild or captive (Maes et

229 al. 2012), sex (Aragón 2011), previous experience (Urszán et al. 2015b), used measures

230 (Videlier et al. 2014; Kelleher et al. 2017) and slightly with age (Urszán et al. 2015b)

231 (see Table 2). The greatest variability was between different arena structures in

232 Lithobates catesbeianus, being lowest in the rock-filled enclosure and highest at the

233 plant-filled enclosure (Smith and Doupnik 2005). When tested with different time gaps

234 between repeated measurements, the differences in the repeatability of activity were not

235 apparent (Maes et al. 2012). Furthermore, overall repeatability of activity of larval and 
236 post-metamorphic amphibians did not differ much, but no study provided the

237 comparison between multiple life stages of the same individuals, probably due to vast

238 differences in locomotor abilities of larval and post-metamorphic anurans.

\section{Exploration}

240 Multiple behaviour patterns were observed for exploration. Most of the newts started

241 the trial with a quick escape response and then commenced with the exploration of the

242 outer ring of the arena, rarely visiting the inner parts. A smaller group was startled at

243 first and then explored the inner parts of the arena, eventually reaching the outer ring.

244 The repeatability of exploration in our study was almost identical to the results reported

245 by Gifford et al. (2014) for Desmognathus brimleyorum, measured in the same time

246 frame of three weeks. Unfortunately, we were not able to test for the reduction in

247 repeatability with time, as they did. Anuran research showed differences in the

248 consistency of exploration between naïve tadpoles of two different age groups and pre-

249 tested tadpoles, latter being the highest (Urszán et al. 2015b). The repeatability of post-

250 metamorphic exploration of Pseudophryne corroboree (Kelleher et al. 2017) did not

251 differ from larval exploration of Lithobates catesbeianus (Carlson and Langkilde 2013)

252 despite different time gaps between repeated measurements. It was also higher than

253 larval exploration of both Rana temporaria (Brodin et al. 2013) and $R$. dalmatina

254 (Urszán et al. 2015b), so there does not seem to be any obvious pattern in its strength.

255 The greatest drawback to the comparison of published results is difference in the 256 definition of exploration. It was defined as a buffer around the trajectory of the 257 individual (Brodin et al. 2013), number of visited squares (this study; Carlson and 258 Langkilde 2013; Gifford et al. 2014) or percentage of visited squares (Urszán et al. 259 2015b). Kelleher et al. (2017) even used three definitions - distance travelled, time 
260 spent mobile and number of mobile events, that all showed different repeatability (Table

261 2). The strength of correlation (repeatability) should therefore not be the main indicator

262 of the suitability of certain measure as the best representative of exploration behaviour.

263 The studies are in need of standardized approaches if they are ever to be compared

264 effectively.

\section{Boldness}

266 In our study, the repeatability of boldness was present only for the escape response,

267 which is a similar measure to that of Carlson and Langkilde (2013), who counted the

268 number of square sides on the inner portion of the test arena crossed by an individual

269 and which is also a measure of thigmotaxis. Their results are less precise, and the

270 estimated coefficient is lower even though measured with the shorter $24 \mathrm{~h}$ breaks

271 between trials (see Table 2). The accuracy of latency of the first movement, as the

272 measure of boldness, was impaired for our study by the inability to consistently raise the

273 glass dome in the centre of the arena at the start of the experiment. We suspect this to be

274 issue in other studies as well, deeming this method impractical. This problem can be

275 mitigated by changing the first movement to a movement longer than one body length

276 (Wilson and Krause 2012), but in our opinion, it is better to choose a completely

277 different option, e.g., shelter use, escape initiation distance or thigmotaxis.

278 Similar consistency of boldness was reported for Ambystoma barbouri and A. texanum

279 (Sih et al. 2003) using shelter use as the preferred measure. Looking at other studies, the

280 consistency of boldness varied greatly from 0 to $77 \%$. The variation was caused by

281 previous experience (Urszán et al. 2015a, 2015b) and the breeding origin (Maes et al.

282 2012) of the study subjects, and probably by the differences in boldness definition

283 (supported by Kelleher et al. 2017). There does not seem to be any difference between 
284 larval and post-metamorphic amphibians or between different time gaps in repeatability

285 measurements (see Table 2).

286 Trial repeatability

287 Activity and exploration significantly decreased with each trial of the experiment, which

288 suggests that habituation may have taken place (but see Carlson and Langkilde 2013).

289 Except for activity, no behavioural trait was repeatable for each trial of the experiment.

290 This could mean that the magnitude of habituation varied individually, i.e., individuality

291 was stronger than habituation (see Fig. 1). For activity, its repeatability for each trial of

292 the experiment was, unexpectedly, followed by low repeatability of both walking and

293 swimming. Other than habituation, another less likely explanation is that the decrease in

294 the expression of behaviour traits could have been caused by insufficient time between

295 the trials of the experiment, allowing newts to remember the last trial. Unfortunately, it

296 was not possible to allow more time between the trials because we feared that newts

297 might switch to the terrestrial phase and change their behaviour. Nevertheless, most

298 amphibian personality studies had an even lower gap between repeated measurements

299 (Table 2). Habituation recovery time is unknown for the studied species. For the

300 common toad, however, Ewert and Kehl (1978) stated that 6-24 h is long enough for

301 recovery from habituation to an artificial rectangular-shaped prey dummy.

\section{Figure 1. Individuality vs. habituation}

303 A - activity between trials, B - exploration between trials, C - escape response between trials. 


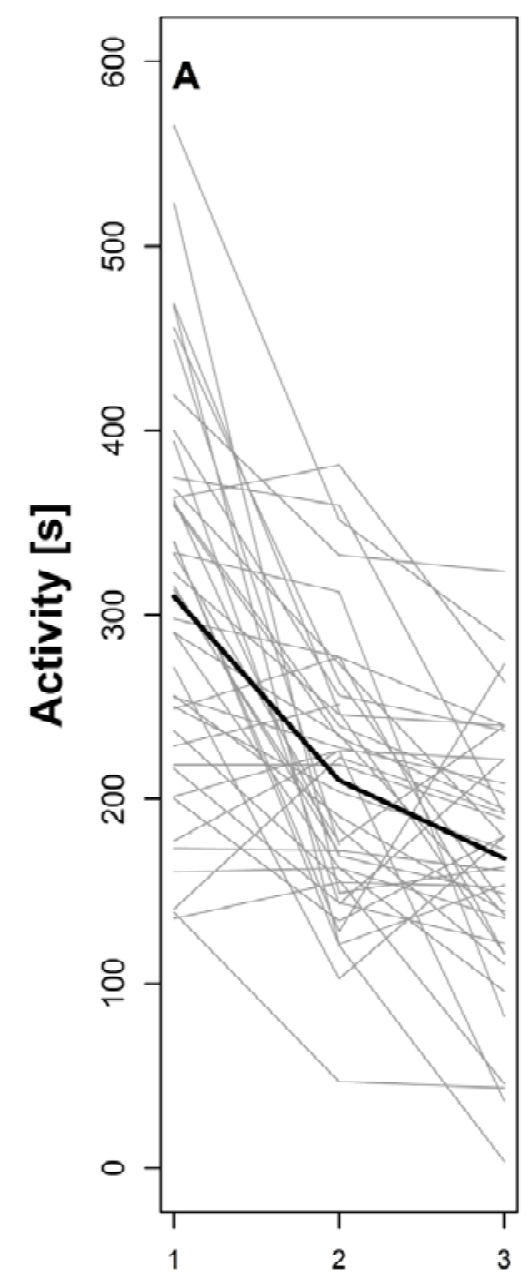

304

305

306

307

308

309

310

\section{Behavioural syndromes}
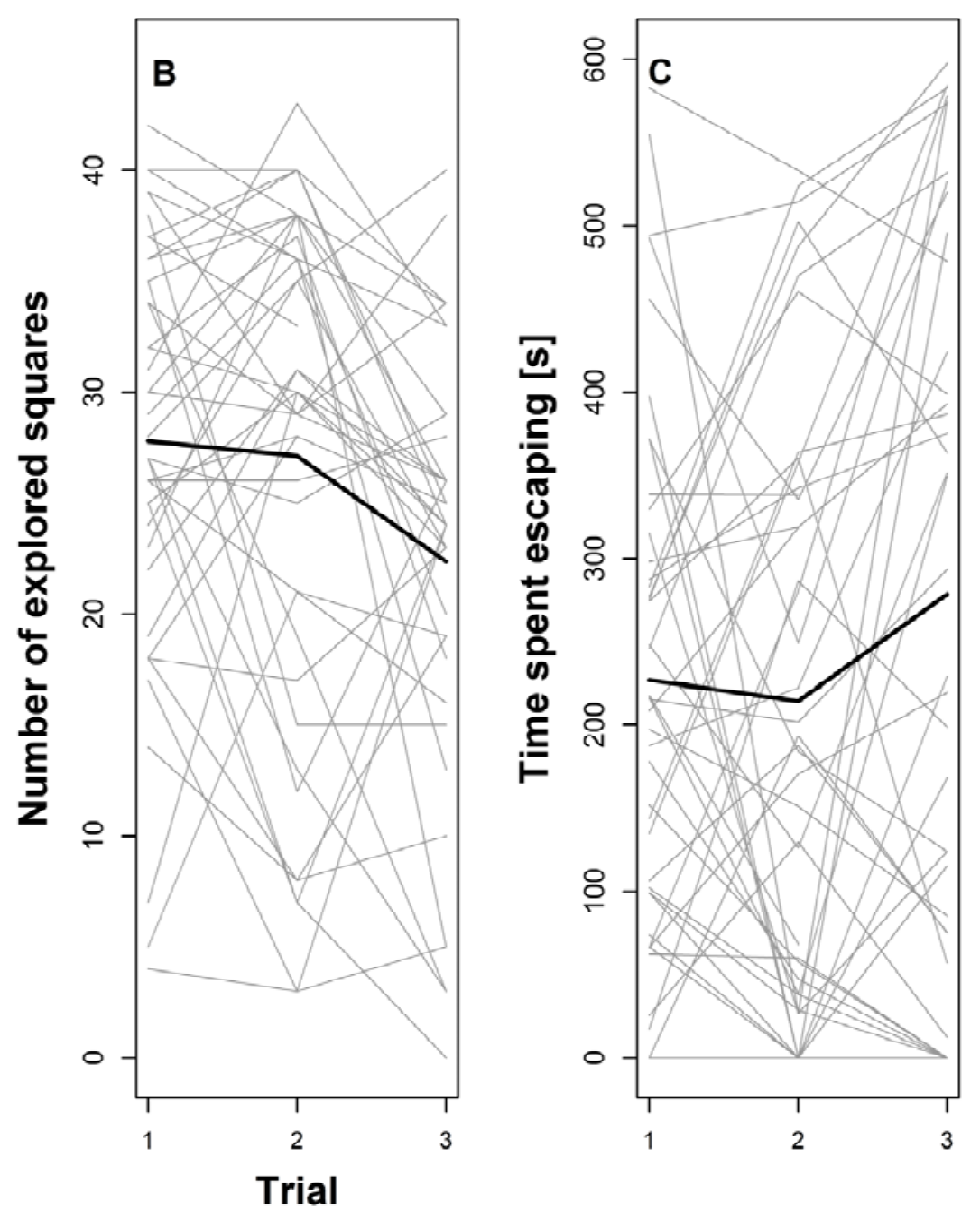

Behavioural syndromes are referred to as suites of correlated behaviours (Sih et al., 2004). According to Kelleher et al. (2018), a total of seven studies assessed behavioural correlations in larval and eight in post-metamorphic amphibians. Activity has been found to correlate with exploration (Koprivnikar et al. 2011; Maes et al. 2012; Wilson and Krause 2012) and boldness (Maes et al. 2012; Wilson and Krause 2012; Urszán et 
311 al. 2015a). Boldness has also been found to correlate with exploration (Maes et al.

312 2012) (but see Brodin et al. 2013), as well as sociability (González-Bernal et al. 2014).

313 Maes et al. (Maes et al. 2012) divided the behaviours using PCA (Principal component

314 analysis) into two axes. The first contained activity and exploration, while the second

315 contained only latency of the first movement. Contrary to their findings, our results

316 show a correlation of all three measured behavioural types (activity, exploration and

317 time spent escaping), potentially creating only one axis (Kendall's $W=0.694, P=$

318 0.0001). These behaviours are causally independent and, even being as a part of a single

319 open field test, do not have to be correlated. More movement does not necessarily

320 translate into more squared explored, nor imply more movement near the edge of the

321 arena. In our case, active individuals tended to explore more and were less bold,

322 spending more time escaping. This behaviour might also be a result of a common

323 selective pressure, favouring individuals with a greater insight on the situation in their

324 home pond. The predation rate in the pond was, however, low (pers. obs.), and thus the

325 pressure might be of a reproductive nature. Increase in locomotion activity has been

326 found to benefit in mate searching (Martin et al. 1989), which might result in a

327 correlation with sociability, but we are not aware of any studies researching

328 aggressivity. Because of the absence of behavioural differences between sexes, this

329 pressure might be beneficial for both males and females or at least not harmful for

330 either. Whatever the cause, correlated behaviours, i.e., behaviours that are part of a

331 syndrome should not be studied in isolation because they develop as a group (Sih et al.

332 2004). To study behaviour syndrome completely, it would also be beneficial to test if

333 the correlations persist in different situations and ecological contexts. 
334 In conclusion, amphibian personality research is sparse, and findings differ considerably

335 in both approach and results. Behavioural consistency is often studied on a small scale

336 in relatively specific conditions, and behavioural correlations are sometimes neglected.

337 We believe that a more complex approach (measuring more types of behaviour) and

338 standardized methodology (i.e., definition of behaviour types, correlation in time and

339 different situations, standard time gap between repeated measurements, number of

340 repeated measurements, duration of experiment and sampling effort, and test arena

341 shape and size) is due. Only then it would be possible to make general assumptions on

342 the global nature and consequences of studied phenomena.

343 Acknowledgements. The study was carried out in accordance with permit SZ-

344 092744/2012KUSK/3 issued by the Regional Office of the Central Bohemian Region of

345 the Czech Republic with the support of grants no. 20164234 and no. 20174216,

346 provided by the Internal Grant Agency of the Faculty of Environmental Sciences, Czech

347 University of Life Sciences Prague.

348 Author contributions. O. Kopecký captured and cared for newts, and together with P.

349 Chajma participated on the execution of the experiment. P. Chajma analysed the data,

350 prepared all figures and tables and together with J. Vojar wrote the main manuscript.

351 All authors reviewed the manuscript.

352 Competing interests. The author(s) declare no competing interests. 
354

355

356

357

358

359

360

361

362

363

364

365

366

367

368

369

370

371

372

373

374

375

376

377

378

379

380

381

382

383

384

385

386

387

388

389

390

391

392

393

394

\section{References}

Aragón P. 2011. The response to the social environment reveals sex-dependent behavioural syndromes in the Bosca's newt (Lissotriton boscai). Journal of Ethology 29: 79-83.

Bates D, Maechler M, Bolker B, Walker S. 2015. Fitting Linear Mixed-Effects Models Using lme4. Journal of Statistical Software 67: 1-48.

Brodin T, Lind M, Wiberg M, Johansson F. 2013. Personality trait differences between mainland and island populations in the common frog (Rana temporaria). Behavioral Ecology and Sociobiology 67: 135-143.

Burns JG. 2008. The Validity of Three Tests of Temperament in Guppies (Poecilia reticulata). Journal of Comparative Psychology 122: 344-356.

Carlson BE, Langkilde T. 2013. Personality Traits Are Expressed in Bullfrog Tadpoles during Open-Field Trials. Journal of Herpetology 47: 378-383.

Carlson BE, Langkilde T. 2014a. No evidence of selection by predators on tadpole boldness. Behaviour 151: 23-45.

Carlson BE, Langkilde T. 2014b. Predation risk in tadpole populations shapes behavioural responses of prey but not strength of trait-mediated indirect interactions. Oikos 123: 1519-1527.

Cole EF, Quinn JL. 2014. Shy birds play it safe: personality in captivity predicts risk responsiveness during reproduction in the wild. Biology Letters 10: 1-4.

Cote J, Clobert J, Brodin T, Fogarty S, Sih A. 2010. Personality-dependent dispersal: characterization, ontogeny and consequences for spatially structured populations. Philosophical transactions of the Royal Society of London. Series B, Biological sciences 365: 4065-4076.

Cote J, Fogarty S, Tymen B, Sih A, Brodin T. 2013. Personality-dependent dispersal cancelled under predation risk. Proceedings of the Royal Society B: Biological Sciences 280: 1-9.

Dingemanse NJ, Réale D. 2005. Natural selection and animal personality. Behaviour 142: 1159-1184.

Dingemanse NJ, de Goede P. 2004. The relation between dominance and exploratory behavior is context-dependent in wild great tits. Behavioral Ecology 15: 10231030.

Ewert JP, Kehl W. 1978. Configurational prey-selection by individual experience in the toad Bufo bufo. Journal of Comparative Physiology 126: 105-114.

Fox J, Weisberg S. 2011. An R Companion to Applied Regression. Sage: Thousand Oaks CA.

Garamszegi LZ, Marko G, Herczeg G. 2013. A meta-analysis of correlated behaviors with implications for behavioral syndromes: relationships between particular behavioral traits. Behavioral Ecology 24: 1068-1080.

Gifford ME, Clay TA, Careau V. 2014. Individual (Co)variation in Standard Metabolic Rate, Feeding Rate, and Exploratory Behavior in Wild-Caught Semiaquatic 

Salamanders. Physiological and Biochemical Zoology 87: 384-396.

González-Bernal E, Brown GP, Shine R. 2014. Invasive cane toads: Social facilitation depends upon an individual's personality. PLOS ONE 9.

Gosling SD. 2001. From mice to men: what can we learn about personality from animal research? Psychological bulletin 127: 45-86.

Gruber J, Brown G, Whiting MJ, Shine R. 2017. Is the behavioural divergence between range-core and range-edge populations of cane toads (Rhinella marina) due to evolutionary change or developmental plasticity? Royal Society Open Science 4.

Harris AP, D'Eath RB, Healy SD. 2009. Environmental enrichment enhances spatial cognition in rats by reducing thigmotaxis (wall hugging) during testing. Animal Behaviour 77: 1459-1464.

Kelleher SR, Silla AJ, Dingemanse NJ, Byrne PG. 2017. Body size predicts betweenindividual differences in exploration behaviour in the southern corroboree frog. Animal Behaviour 129: 161-170.

Kelleher SR, Silla AJ, Byrne PG. 2018. Animal personality and behavioral syndromes in amphibians $\square$ : a review of the evidence, experimental approaches, and implications for conservation.

Koprivnikar J, Gibson CH, Redfern JC. 2011. Infectious personalities: behavioural syndromes and disease risk in larval amphibians. Proceedings of the Royal Society B: Biological Sciences 279: 1544-1550.

Maes J, Van Damme R, Matthysen E. 2012. Individual and among-population variation in dispersal-related traits in Natterjack toads. Behavioral Ecology 24: 521-531.

Martin E, Joly P, Bovet P. 1989. Diel pattern of activity in the alpine newt (Triturus Alpestris, amphibia-urodela) during the aquatic phase. Biology of Behaviour 14: $116-131$.

Nakagawa S, Schielzeth H. 2010. Repeatability for Gaussian and non-Gaussian data: A practical guide for biologists. Biological Reviews 85: 935-956.

Noldus. 2010. The Observer XT. Reference manual version 10. Noldus Information Technology, Wageningen, Wageningen.

R Core Team. 2016. R: A Language and Environment for Statistical Computing.

Réale D, Reader SM, Sol D, McDougall PT, Dingemanse NJ. 2007. Integrating animal temperament within ecology and evolution. Biological Reviews of the Cambridge Philosophical Society 82: 291-318.

Sih A, Kats LB, Maurer EF. 2003. Behavioural correlations across situations and the evolution of antipredator behaviour in a sunfish-salamander system. Animal Behaviour 65: 29-44.

Sih A, Bell A, Johnson J, Ziemba R. 2004. Behavioral syndromes: an integrative overview. The Quarterly Review of Biology 79: 241-277.

Smith GR, Doupnik BL. 2005. Habitat use and activity level of large American bullfrog tadpoles: Choices and repeatability. Amphibia Reptilia 26: 549-552.

Stoffel MA, Nakagawa S, Schielzeth H. 2017. An introduction to repeatability 
436 estimation with rptR. : 1-33.

437 Urszán TJ, Garamszegi LZ, Nagy G, Hettyey A, Török J, Herczeg G. 2015a. No

438 personality without experience? A test on Rana dalmatina tadpoles. Ecology and

$439 \quad$ Evolution 5: 5847-5856.

440 Urszán TJ, Török J, Hettyey A, Garamszegi LZ, Herczeg G. 2015b. Behavioural 441 consistency and life history of Rana dalmatina tadpoles. Oecologia 178: 129-140.

442 Videlier M, Bonneaud C, Cornette R, Herrel A. 2014. Exploration syndromes in the 443 frog Xenopus (Silurana) tropicalis: Correlations with morphology and 444 performance? Journal of Zoology 294: 206-213.

445 Videlier M, Cornette R, Bonneaud C, Herrel A. 2015. Sexual differences in exploration 446 behavior in Xenopus tropicalis? Journal of Experimental Biology 218: 1733-1739.

447 Wilson ADM, Krause J. 2012. Personality and metamorphosis: Is behavioral variation 448 consistent across ontogenetic niche shifts? Behavioral Ecology 23: 1316-1323.

449 Winandy L, Denoël M. 2015. The aggressive personality of an introduced fish affects $450 \quad$ foraging behavior in a polymorphic newt. Behavioral Ecology 26: 1528-1536. 
453 Table 2. | Summary of amphibian personality studies effect sizes

\begin{tabular}{|c|c|c|c|c|c|c|c|c|}
\hline \multirow[t]{2}{*}{ Species } & \multirow[t]{2}{*}{ Life stage } & \multicolumn{3}{|c|}{ Repeatability } & \multirow{2}{*}{$\begin{array}{l}\text { Sample } \\
\text { size }\end{array}$} & \multirow[t]{2}{*}{ Trials } & \multirow{2}{*}{$\begin{array}{l}\text { Type of } \\
\text { consistency }\end{array}$} & \multirow[t]{2}{*}{ Reference } \\
\hline & & Activity & Exploration & Boldness & & & & \\
\hline \multirow[t]{2}{*}{$\begin{array}{l}\text { Rana } \\
\text { temporaria }\end{array}$} & larval & - & - & $r=0.34^{*}$ & 60 & 2 & $\begin{array}{l}\text { temporal } \\
\text { (12 days gap) }\end{array}$ & $\begin{array}{l}\text { Brodin et al. } \\
(2013)\end{array}$ \\
\hline & $\begin{array}{l}\text { larval/post- } \\
\text { metamorphic }\end{array}$ & - & $\mathrm{r}=0.25$ & $\mathrm{r}=0.25$ & 60 & 2 & $\begin{array}{l}\text { across life } \\
\text { stages }\end{array}$ & \\
\hline \multirow[t]{3}{*}{$\begin{array}{l}\text { Rana } \\
\text { dalmatina }\end{array}$} & larval & $\mathrm{ICC}=0.4^{*}$ & $\mathrm{ICC}=0.01$ & $\mathrm{ICC}=0.01$ & 19 & 3 & $\begin{array}{l}\text { temporal } \\
\text { (1 day gap), } \\
\text { naive } \\
\text { individuals } \\
\text { (11 days age), }\end{array}$ & $\begin{array}{l}\text { Urszán et al. } \\
\text { (2015b) }\end{array}$ \\
\hline & & $\mathrm{ICC}=0.55^{*}$ & $\mathrm{ICC}=0.24 *$ & $\mathrm{ICC}=0.09$ & 18 & 3 & $\begin{array}{l}\text { temporal } \\
\text { (1 day gap), } \\
\text { naive } \\
\text { individuals } \\
\text { (Gosner stage } \\
32-36 \text { ) }\end{array}$ & \\
\hline & & $\mathrm{ICC}=0.3^{*}$ & $\mathrm{ICC}=0.39 *$ & $\mathrm{ICC}=0.24$ & 18 & 3 & $\begin{array}{l}\text { temporal } \\
\text { (1 day gap), } \\
\text { pre-tested } \\
\text { individuals } \\
\text { (Gosner stage } \\
\text { 32-36) }\end{array}$ & \\
\hline \multirow[t]{4}{*}{$\begin{array}{l}\text { Rana } \\
\text { dalmatina }\end{array}$} & larval & $\mathrm{ICC}=0$ & - & $\mathrm{ICC}=0.11$ & 18 & 3 & $\begin{array}{l}\text { temporal } \\
\text { (1 day gap), } \\
\text { no odour }\end{array}$ & $\begin{array}{l}\text { Urszán et al. } \\
\text { (2015a) }\end{array}$ \\
\hline & & $\mathrm{ICC}=0.27$ & & $\mathrm{ICC}=0.15$ & 18 & 3 & $\begin{array}{l}\text { temporal } \\
\text { (1 day gap), } \\
\text { conspecifics' } \\
\text { odour }\end{array}$ & \\
\hline & & $\mathrm{ICC}=0.56^{*}$ & & $\mathrm{ICC}=0.3^{*}$ & 20 & 3 & $\begin{array}{l}\text { temporal } \\
\text { (1 day gap), } \\
\text { predators' } \\
\text { odour }\end{array}$ & \\
\hline & & $\mathrm{ICC}=0.53^{*}$ & & $\mathrm{ICC}=0.2$ & 17 & 3 & $\begin{array}{l}\text { temporal } \\
\text { (1 day gap), } \\
\text { conspecifics' } \\
\text { and predators' } \\
\text { odour }\end{array}$ & \\
\hline $\begin{array}{l}\text { Pelophylax } \\
\text { ridibundus }\end{array}$ & $\begin{array}{l}\text { post- } \\
\text { metamorphic }\end{array}$ & $\mathrm{r}_{\mathrm{s}}=0.8^{*}$ & - & $r_{s}=0.56^{*}$ & 50 & 2 & $\begin{array}{l}\text { temporal } \\
\text { (1 day gap) }\end{array}$ & $\begin{array}{l}\text { Wilson and } \\
\text { Krause } \\
(2012)\end{array}$ \\
\hline \multirow[t]{2}{*}{$\begin{array}{l}\text { Lithobates } \\
\text { catesbeianus }\end{array}$} & larval & $\mathrm{r}=0.36^{*}$ & - & - & 19 & 3 & $\begin{array}{l}\text { temporal (all } \\
\text { during one } \\
\text { week), } \\
\text { plant } \\
\text { treatment }\end{array}$ & $\begin{array}{l}\text { Smith and } \\
\text { Doupnik } \\
(2005)\end{array}$ \\
\hline & & $r=-0.15$ & - & - & 19 & 3 & $\begin{array}{l}\text { temporal (all } \\
\text { during one } \\
\text { week), } \\
\text { rock treament }\end{array}$ & \\
\hline
\end{tabular}




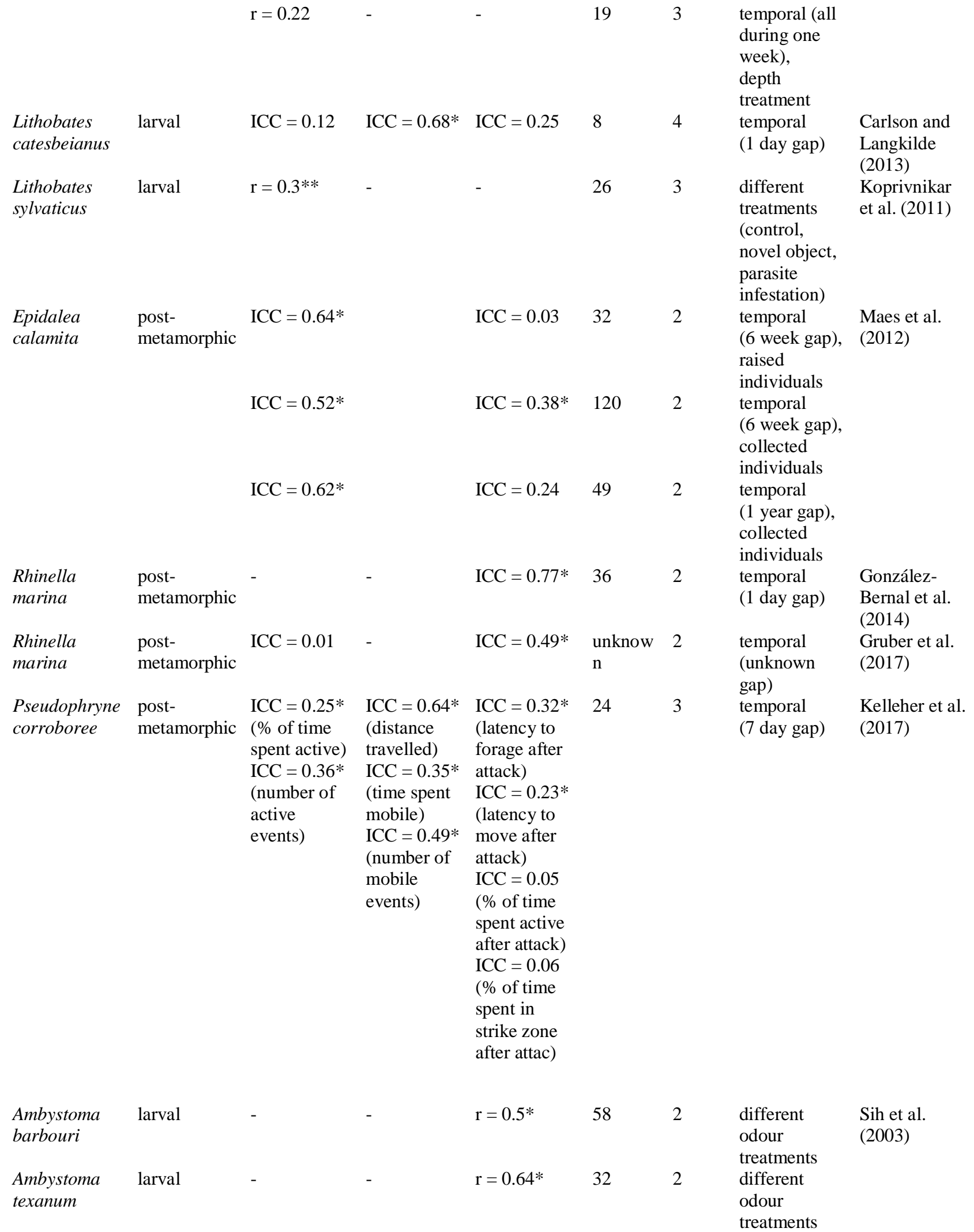




\begin{tabular}{|c|c|c|c|c|c|c|c|c|}
\hline \multirow[t]{3}{*}{$\begin{array}{l}\text { Desmognathus } \\
\text { brimleyorum }\end{array}$} & \multirow[t]{3}{*}{$\begin{array}{l}\text { post- } \\
\text { metamorphic }\end{array}$} & - & $\mathrm{r}=0.39^{*}$ & - & 19 & 2 & $\begin{array}{l}\text { temporal } \\
(3 \text { weeks })\end{array}$ & \multirow[t]{3}{*}{$\begin{array}{l}\text { Gifford et al. } \\
\text { (2014) }\end{array}$} \\
\hline & & - & $r=0.3$ & - & 19 & 2 & $\begin{array}{l}\text { temporal } \\
\text { (6 weeks) }\end{array}$ & \\
\hline & & - & $r=0.15$ & - & 19 & 2 & $\begin{array}{l}\text { temporal } \\
\text { (9 weeks) }\end{array}$ & \\
\hline $\begin{array}{l}\text { Lissotriton } \\
\text { boscai }\end{array}$ & $\begin{array}{l}\text { post- } \\
\text { metamorphic }\end{array}$ & $\begin{array}{l}\mathrm{r}=0.77 * \\
\text { (males) } \\
\mathrm{r}=0.05 \\
\text { (females) }\end{array}$ & - & - & $15+15$ & 2 & $\begin{array}{l}\text { different } \\
\text { odour } \\
\text { treatments }\end{array}$ & $\begin{array}{l}\text { Aragón } \\
\text { (2011) }\end{array}$ \\
\hline $\begin{array}{l}\text { Lissotriton } \\
\text { vulgaris }\end{array}$ & $\begin{array}{l}\text { post- } \\
\text { metamorphi } \\
\text { c }\end{array}$ & $\begin{array}{l}\text { ICC }=0.19 * \\
\text { (activity) } \\
\text { ICC }=0.25 * \\
\text { (walking) } \\
\text { ICC }=0.39 * \\
\text { (swimming) }\end{array}$ & $\mathrm{ICC}=0.4^{*}$ & $\begin{array}{l}\text { ICC }=0.12 \\
\text { (latency of } \\
\text { the first } \\
\text { movement) } \\
\text { ICC }=0.48^{*} \\
\text { (thigmotaxis } \\
\text { ) }\end{array}$ & 42 & 3 & $\begin{array}{l}\text { temporal } \\
\text { (6 day gap) }\end{array}$ & This study \\
\hline $\begin{array}{l}\text { Silurana } \\
\text { tropicalis }\end{array}$ & $\begin{array}{l}\text { post- } \\
\text { metamorphic }\end{array}$ & no values* & no values* & no values* & 37 & 3 & $\begin{array}{l}\text { temporal } \\
\text { (4 hours) }\end{array}$ & $\begin{array}{l}\text { Videlier et al } \\
\text { (2014) }\end{array}$ \\
\hline $\begin{array}{l}\text { Silurana } \\
\text { tropicalis }\end{array}$ & $\begin{array}{l}\text { post- } \\
\text { metamorphic }\end{array}$ & no values* & no values* & no values* & 98 & 3 & $\begin{array}{l}\text { temporal } \\
\text { (4 hours) }\end{array}$ & $\begin{array}{l}\text { Videlier et al } \\
\text { (2015) }\end{array}$ \\
\hline
\end{tabular}

454 Life stage - stage of individual development (larval - tadpoles, larvae; post-metamorphic - juveniles, 455 adults)

456 Trials - number of repeated measurements

457 ICC - intraclass correlation coefficient

$458 \mathrm{r}$ - Pearson's correlation coefficient

$459 \quad \mathrm{r}_{\mathrm{s}}$ - Spearman's correlation coefficient

$460 *$ The result is statistically significant $(\alpha=0.05)$

$461 * *$ The result was obtained by conversion of supplemented Pearson's $\chi^{2}$ to Pearson's $\mathrm{r}$ and is statistically

462 significant $(\alpha=0.05)$ 